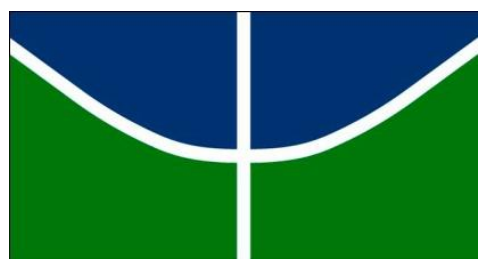

UNIVERSIDADE DE BRASÍLIA

INSTITUTO DE CIÊNCIA POLÍTICA

Maria Teresa Ruas Coelho

A MÍDIA COMO ATOR RELEVANTE EM PROCESSOS DE TRANFORMAÇÃO SOCIAL

Brasília - DF 
Maria Teresa Ruas Coelho

\title{
A MÍDIA COMO ATOR RELEVANTE EM PROCESSOS DE TRANFORMAÇÃO SOCIAL
}

Monografia de conclusão de curso apresentada para o bacharelado em Ciência Política do Instituto de Ciência Política da Universidade de Brasília.

Orientador: Prof. Dr. Thiago Aparecido Trindade

\author{
Brasília - DF
}

2017 


\section{AGRADECIMENTOS}

Agradeço, primeiramente, a todas e todos os professores, colegas e funcionários da universidade que participaram da construção da minha trajetória e da minha formação durante a graduação em Ciência Política.

Ao professor Thiago Aparecido Trindade, pela orientação durante boa parte da minha graduação e pela amizade.

Aos tantos amigos e amigas que me acompanharam, apoiaram e tornaram a vida mais leve.

Ao meu pai, Marcus Vinícius Carvalho Coelho, e minha irmã, Maria Clara Ruas Coelho, que mais de perto me deram o suporte para que hoje eu esteja concluindo essa graduação.

E, finalmente, à minha mãe, Mônica de Cássia Ruas Coelho, e minha avó, Leonídia Orlinda Ruas, por tudo. 


\section{RESUMO}

A mídia tornou-se ator essencial para o entendimento do funcionamento das sociedades contemporâneas. Por isso, propomos neste trabalho analisar a capacidade da mídia em barrar ou impulsionar transformações sociais empreendidas através do ativismo realizado por grupos dominados. Nesse intento, discutimos as relações entre a mídia e o ativismo, separando o estudo entre os meios de comunicação tradicionais e as novas tecnologias de informação comunicação. Utilizamos também de um estudo de caso com a organização não-governamental Engajamundo de modo a aplicar empiricamente as discussões teóricas empreendidas.

Palavras-chave: mudança social; ativismo; mídia; internet; novas tecnologias de comunicação e informação. 


\begin{abstract}
The media has become an essential actor for understanding the functioning of contemporary societies. Therefore, we propose in this work to analyze the capacity of the media to bar or to promote social transformations undertaken through the activism carried out by dominated groups. In this attempt, we discussed the relationship between media and activism, separating the study between traditional media and new information communication technologies. We also use a case study with the nongovernmental organization Engajamundo in order to empirically apply the theoretical discussions undertaken.
\end{abstract}

Key-words: social change; activism; media; internet; new communication and information technologies. 


\section{SUMÁRIO}

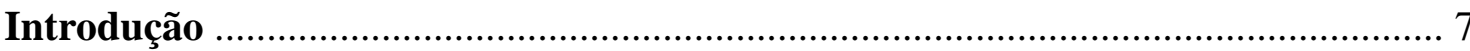

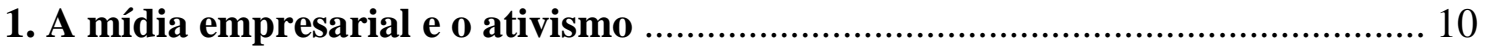

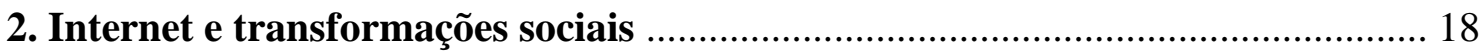

3. A Engajamundo e o uso da internet para o ativismo ......................................... 29

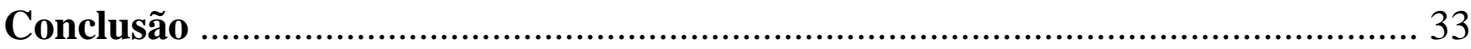

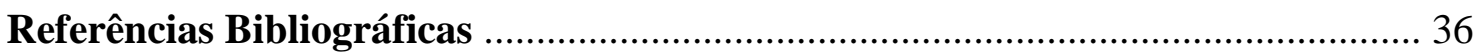




\section{INTRODUÇÃO}

Em se tratando de mudanças sociais sabe-se que elas podem ocorrer tanto pela ação daqueles excluídos social, econômica ou politicamente, quanto por determinação das elites políticas e econômicas (SZTOMPKA, 1995, p. 303-304). Nesse sentido, costuma-se pensar na oposição entre Estado e a população engajada em lutas sociais, em antagonismos de classe ou mesmo na oposição entre ricos e pobres. Estas polarizações, apesar de acentuarem atores e relações de poder e dominação fundamentais da dinâmica estabelecida no capitalismo e nas democracias liberais modernas, não são capazes de iluminar o desenrolar das transformações sociais em sua completude. O esforço para essa apreensão requer que outros atores e processos que permeiam o curso transformacional sejam considerados, dentre eles, os media e seu papel na produção informacional e na construção de interpretações de uma realidade social.

Os meios de comunicação de massa encontram os princípios de sua configuração atual do século XIX para o XX, período em que a indústria jornalística encontra o ambiente propício para o seu desenvolvimento. O crescimento considerável no número de alfabetizados somado às inovações técnicas, fruto da industrialização recente, permitiram um salto na produção e comercialização de jornais. As notícias ganharam, então, uma dimensão internacional e a produção jornalística passa a ser domínio de grandes corporações e agências, que respondem, dentre outros, a imperativos econômicos (THOMPSON, 1995; JASPER, 2016).

O posterior surgimento da difusão por rádio, da televisão e, mais recentemente, das novas tecnologias de informação e comunicação, é parte desse processo de avanço técnico impulsionado pela industrialização e representou mudanças profundas nas formas de sociabilidade, na política e mesmo nas configurações das fronteiras nacionais (THOMPSON, 1995).

Tendo em vista que movimentos contestatórios precisam mobilizar pessoas que se juntem às suas ações - ou que, ao menos, apóiem suas causas - e que buscam transformar determinadas questões em problemas sociais, discutidos publicamente e enfrentados de forma conjunta, também para esses movimentos é imperioso o acesso aos meios de comunicação. Afinal, os media representam a possibilidade de comunicação com pessoas que estão além dos círculos sociais mais imediatos individuais e "tornaram-se espaços de disputas para a difusão de concepções, visões de 
mundo, verdades e versões sobre os diversos fatos políticos (BATALHA, 2010, pp. 38; JASPER, 2016; PEREIRA, 2011)”.

Partindo da premissa de que o acesso aos media é essencial ao ativismo contemporâneo e de que o ativismo empreendido por grupos excluídos é o requisito essencial para que mudanças sociais aconteçam, a centralidade da mídia, para este trabalho, está em seu poder de contribuir para o sucesso ou para o fracasso de mudanças sociais.

Com esse objetivo, estruturamos o trabalho na divisão entre os meios de comunicação tradicionais $\mathrm{e}$ as chamadas novas tecnologias de comunicação e informação (TICs), com enfoque na internet.

No primeiro capítulo trataremos da relação de movimentos de contestação especificamente com a mídia hegemônica. Para isso, discutiremos sobre o processo de produção informacional, para, em seguida, compreender as especificidades da produção realizada na mídia hegemônica, que cria empecilhos ao acesso de grupos ativistas.

No segundo capítulo, tendo Manuel Castells como principal referência, introduziremos as TICs na discussão no intento de compreender as possibilidades e limites que elas representariam para o ativismo político e para os processos de mudanças sociais.

No terceiro capítulo, por fim, aliaremos a discussão realizada no capítulo anterior a um estudo de caso ${ }^{1}$ sobre a organização não-governamental (ONG) Enjamundo, de modo a observar empiricamente os impactos da internet no ativismo contemporâneo.

A escolha dessa ONG deu-se, primeiro, por sua ampla utilização das redes virtuais no processo de mobilização, como meio de comunicação, arrecadação de fundos financeiros por doações, para arquivamento e compartilhamento de dados, visibilidade de pautas defendidas e pressão política (por meio dos chamados tuitaços, por exemplo).

Segundo, a organização se apresenta, em sua página oficial e nas falas dos entrevistados, como uma rede, conceito que será explicado neste trabalho e que serve de base à teoria de Castells e de outros autores mais otimistas com as possibilidades

\footnotetext{
${ }^{1}$ Como orientação sobre o uso do estudo de caso como estratégia de implementação para pesquisa científica conferir: YIN, Robert K. Estudo de Caso: Planejamento e Métodos. Porto Alegre: Bookman, 2005; FLYVBJERG, Bent. Caso study. In: The Sage Handbook of Qualitative Research. Thousand Oaks, CA: Sage, 2011, chapter 17, pp. 301-316.
} 
supostamente criadas pela internet. Além disso, a Engajamundo ressalta, tanto em sua página oficial quanto nas falas dos entrevistados certa desconfiança em relação às instituições, ressaltando a inexistência de relações com partidos ou empresas, característica que, para Castells (2006, 2013), é nota característica dos grupos ativistas.

Por fim, sendo uma organização jovem, predominantemente urbana e sem a tradicional caracterização dos movimentos populares de resistência, acreditamos que seria interessante pesquisar a existência e o grau dos limites para o uso da internet à favor do ativismo na Engajamundo.

Para efetuar essa pesquisa, partimos do recolhimento de informações contidas no site oficial da $\mathrm{ONG}^{2}$. Posteriormente, realizamos algumas entrevistas com membros da organização. Foram entrevistados a coordenadora de redes e uma das fundadoras da ONG, uma coordenadora do GT de Clima e um coordenador do GT de Gênero.

Para tanto, utilizamos de um questionário semi-estruturado ${ }^{3}$ que serviu de roteiro para todos os entrevistados. As duas primeiras entrevistas ocorreram por meio Google Hangouts e a terceira pessoalmente. Além disso, participamos de uma reunião do GT de Gênero, feita via Google Hangouts.

\footnotetext{
${ }^{2}$ www.enjamundo.org

${ }^{3}$ Sobre entrevistas semi-estruturadas, conferir: DUARTE, Rosália. Entrevistas em pesquisas qualitativas. Editora UFPR. Revista Educar, Curitiba, n. 24, 2004, pp. 213-225.
} 


\section{CAPÍTULO 1 - A MÍDIA EMPRESARIAL E O ATIVISMO}

Considerando a amplitude da influência alcançada pelos media na dinâmica das sociedades modernas, a compreensão de seus efeitos na realidade social tornou-se indispensável. O surgimento de estudos preocupados em dimensionar os efeitos da imprensa possui uma trajetória relativamente longa. Podemos buscar ainda no século XIX, no ensaio Opinião e Conversação do sociólogo Daniel Tarde, o início dessa preocupação em analisar a influência da imprensa na formação da opinião pública e, posteriormente, no livro Public Opinion (1922), de Lippman, o trabalho que é comumente considerado como precursor do que se conformaria como a hipótese do agenda-setting (AZEVEDO, 2004).

Nenhum desses autores, entretanto, estenderam suas análises a uma tentativa de compreender como tal influência operaria de fato. Este esforço teve lugar somente com a formulação da "teoria da agulha hipodérmica", também conhecida por magic bullet (bala mágica), a primeira abordagem hegemônica de estudos comunicacionais voltados aos efeitos da imprensa (AZEVEDO, 2004).

Com forte influência da Psicologia Social estadunidense e do behaviorismo que, à época, era seu ramo dominante, tal paradigma apresenta os meios de comunicação de massa como superpoderosos, capazes de produzir efeitos imediatos nas pessoas e, portanto, na opinião pública. Assim, estabelece-se uma relação de estímuloresposta, em que a audiência recebe, passivamente, o que a mídia veicula, sendo esta capaz de atingir igualmente a todos os que forem expostos às suas mensagens. Em uma palavra, a mídia teria um poder extraordinário de manipulação (AZEVEDO, 2004).

Esta primeira linha argumentativa tornou-se dominante no campo comunicacional sem, contudo, permanecer imune a críticas, que se colocam tanto à afirmação de que os media teriam o poder de produzir "efeitos ilimitados", ou seja, de provocar comportamentos ou percepções de forma previsível e intencional em seus consumidores, quanto por retratar a audiência com uma massa indiferenciada, passiva e acrítica, desconsiderando contextos sociais e relações interpessoais (AZEVEDO, 2004; WOLF, 2003).

A teoria dos "efeitos ilimitados", destarte, cederia lugar a um novo paradigma nos estudos dos efeitos comunicacionais. A pesquisa de Lazarsfeld, publicada em The people's choice (1944), sobre os impactos da mídia na formulação de preferências eleitorais marcou essa transição ao constatar a importância das relações 
travadas cotidianamente pelo "cidadão comum" na construção destas preferências. Os efeitos mediáticos seriam, portanto, limitados (AZEVEDO, 2004).

Há que se considerar, entretanto, que a complexidade das sociedades modernas, nas quais uma infinidade de eventos acontece simultaneamente em diferentes espaços, implica que as pessoas são impossibilitadas de ter contato com grande parte da realidade social. Deste modo, existe uma intensa "dependência cognitiva" em relação à mídia, que figura como a única possibilidade de obtenção de conhecimentos para além das experiências cotidianas dos indivíduos ou de seu círculo social imediato (BIROLI, 2011; MCCOMBS E SHAW, 1972; WOLF, 2003).

Dando ênfase a este aspecto, sem, no entanto, recair no paradigma dos "efeitos ilimitados", a hipótese do agenda-setting sobrepuja as teorias anteriores. Com fortes influências sociológicas, a citada hipótese, que encontra seus princípios, como dito anteriormente, já em Lippman, é aplicada empiricamente, nomeada e mais claramente conceitualizada por Maxwell E. McCombs e Donald L. Shaw, em 1972 (AZEVEDO, 2004; MCCOMBS E SHAW, 1972).

Esse novo paradigma foi responsável por incluir nos estudos sobre os efeitos da mídia aspectos sociais psicológicos e interrelacionais dos indivíduos, que não são condicionados pelos meios de comunicação e que impactam na recepção que cada consumidor teria da informação (MCCOMBS E SHAW, 1972; WOLF, 2003).

Para a abordagem do agenda-setting, a atuação dos media não ocorre de forma imediata e pontual, como apreagoado anteriormente, mas, bem ao contrário, de forma contínua no espaço e no tempo, agindo a longo prazo sobre os quadros cognitivos que os indivíduos usam para interpretar a realidade. Há, portanto, a passagem dos "efeitos limitados" para os "efeitos cumulativos", que enfatizam o caráter processual da ação dos efeitos mediáticos (AZEVEDO, 2004; WOLF, 2003).

O entendimento seria o de que por mais que os meios de comunicação de massa não tenham o poder de decidir como as pessoas irão pensar, eles têm largo poder na definição, a partir da hierarquização de quais acontecimentos do mundo concreto merecem ser noticiados e da persistência em noticiá-los, quais aspectos da realidade social são mais relevantes e merecem sua atenção (AZEVEDO, 2004; WOLF, 2003). Como explicita Cohen, "the press may not be sucessful intelling its readers what to think, but it is stunningly successful in telling its readers what to think about" (COEHN, 1963, p. 13 apud MCCOMBS E SHAW, 1972, p.177). 
A incorporação da noção de enquadramento na abordagem do agendasetting (e pelos próprios McCombs e Shaw), por sua vez, deu-se em resposta a críticas relativas à incapacidade de sua formulação inicial de iluminar os possíveis impactos que a forma como os temas são noticiados têm nos receptores. Assim, como explicita Azevedo (2004, p.53):

Com a adoção da perspectiva do framing, a famosa frase de Cohen deveria ser modificada para incorporar a afirmação de que a mídia não apenas nos diz o que pensar (o primeiro nível da agenda-setting), mas também nos diz como pensar sobre algo (o segundo nível da agenda-setting).

Como ocorreu com o agenda-setting, a noção de enquadramento surgiu como alternativa, e, posteriormente, como substituta a uma abordagem, então, hegemônica: o "paradigma da objetividade". De acordo com esta linha argumentativa, a mídia, para bem servir à democracia e à sua função informacional, deveria ser objetiva e imparcial (PORTO, 2004, p. 75).

A superação do entendimento dos media como um mero canal, uma arena neutra de comunicação entre o Estado e o âmbito privado (ou, de forma mais restrita, entre os políticos e o "cidadão comum"), e como responsável pelo noticiamento dos fatos da realidade social, passou pela compreensão de que a complexidade da realidade concreta das sociedades modernas impossibilita que a mídia possa noticiá-la por completo (BIROLI e MIGUEL, 2010a, p. 61-70; WOLF, 2003).

A consequência disso é que todo um processo de seleção, que passa por uma hierarquização do que é relevante ou não de ser publicado, é monopolizado pelos jornalistas, que, afinal, também estão inseridos em contextos sociais específicos e em empresas midiáticas inseridas em uma lógica capitalista (BIROLI e MIGUEL, 2010a, p. 61-70; WOLF, 2003).

Desta compreensão surge o framing, que é conceituado de forma condensada e bastante pertinente a estudos de efeitos midiáticos na formulação de Entman:

\footnotetext{
O enquadramento envolve essencialmente seleção e saliência. Enquadrar significa selecionar alguns aspectos de uma realidade percebida e fazê-los mais salientes em um texto comunicativo, de forma a promover uma definição particular do problema, uma interpretação causal, uma avaliação moral e/ou uma recomendação de tratamento para o item descrito (ENTMAN, 1994, p. 294apud PORTO, 2004, p.82).
}

Com base nesta definição, vale destacar que a seleção implica não só que determinadas facetas da realidade serão publicadas, mas também que, 
concomitantemente, outras serão excluídas. Já por saliência, Entman entende que os media trabalham para que as notícias produzidas sejam "significantes ou memoráveis para a audiência” (ENTMAN, 1993, p. 53), e explica como isso ocorre:

Texts can make bits of information more salient by placement or repetition, or by associating them with culturally familiar symbols. However, even a single unillustrated appearance of a notion in an obscure part of the text can be highly salient, if it comports with the existing schemata in a receiver's belief systems. By the same token, an idea emphasized in a text can be difficult for receivers to notice, interpret, or remember because of their existing schemata. For our purposes, schemata and closely related concepts such as categories, scripts, or stereotypes connote mentally stored clusters of ideas that guide individuals' processing of information (ENTMAN, 1993, p. 53).

Fica claro, portanto, que, diferente da noção de uma mídia manipulativa, os efeitos comunicacionais pressupõem um processo de interação entre emissores e receptores, em que o meio social e cultural é colocado como aspecto central de modo a ressaltar que não há garantia de que as mensagens veiculadas serão interpretadas e aceitas de forma indiferenciada pela audiência e exatamente da forma com que, supostamente, intecionada pelos jornalistas e pelas empresas nas quais trabalham (ENTMAN, 1993; PORTO, 2004).

Assim, agendamento e enquadramento agiriam juntos, um estabelecendo os termos em que o conteúdo moldado pelo outro impactaria na audiência, e os estudos de enquadramento seriam extremamente relevantes, já que "(...) directs our attention to the details of just how a communicated text exerts its power" (ENTMAN, 1993, p. 55-56; PORTO, 2004).

Nesse cenário, grupos ativistas precisam do acesso aos meios de comunicação para difusão de suas próprias interpretações da realidade, para mobilização e para comunicação - tanto interna, quanto com o restante da sociedade - e também disputam esse espaço de poder que é a mídia (JASPER, 2016). Partindo do pressuposto de que os meios de comunicação tradicionais estão concentrados nas mãos das elites políticas e econômicas, Pereira (2011) afirma que esse acesso poderia dar-se de duas maneiras: chamando a atenção da grande mídia por meio de ações passíveis de serem consideradas noticiáveis ou desenvolvendo as suas próprias mídias.

Ocorre que a mídia tradicional, via de regra, apresenta uma série de empecilhos à inserção de movimentos contestatórios e de suas versões sobre os eventos da realidade social. A partir dessa afirmação, nos deteremos brevemente em alguns dos fatores que levam à exclusão sistemática desses movimentos da grande mídia. 
Primeiramente, é importante ressaltar que todo meio de comunicação possui um limite de espaço ou de tempo que restringe o volume de informações a ser publicado ou transmitido, o que implica um processo de seleção de acontecimentos e informações da realidade concreta a serem noticiados. Essa seleção significa não só que determinadas facetas da realidade serão publicadas, mas também que, concomitantemente, outras serão excluídas, correndo o risco de serem até mesmo invisibilizadas (BIROLI E MIGUEL, 2010a; ENTMAN, 1993; WOLF, 2003).

No caso da mídia empresarial, entretanto, observa-se que essa exclusão é predominantemente imputada a grupos que passam, anteriormente, por diversos tipos de exclusão na realidade social, dentre eles os movimentos disruptivos, principais agentes das transformações sociais (BIROLI E MIGUEL, 2010b; BIROLI, 2011).

Relacionado a isso, está o fato de que a grande mídia é composta por empresas de comunicação inseridas em uma lógica capitalista. A busca pelo lucro, dessa feita, é objetivo fundamental para esses canais informacionais e, nessa lógica, matérias e assuntos que não sejam de interesse de seus patrocinadores ou que contradigam as estruturas capitalistas provavelmente serão excluídas (BATALHA, 2010; MIGUEL, 2002; JASPER, 2016; CASTELLS, 2013; BIROLI E MIGUEL, 2010a).

Outro fator relevante é que os jornalistas precisam lidar com a "necessidade de se ter um fluxo constante e seguro de notícias", o que afeta a busca por informações e, consequentemente, a escolha de onde, ou ainda, com quem essas informações serão obtidas, ou seja, a escolha das fontes (WOLF, 2003, p. 231; JASPER, 2016).

Essa escolha não considera apenas a óbvia necessidade de que as fontes sejam contatáveis e capazes de fornecer o material necessário, mas, principalmente, que sejam confiáveis, respeitáveis, que suas informações sejam fidedignas, a fim de evitar questionamentos do público quanto à veracidade do que está sendo noticiado, e que não necessitem passar por grandes adaptações para que se encaixem nos moldes organizacionais do meio de comunicação em que serão publicados (WOLF, 2003).

Tais critérios de escolha das fontes, além de evitarem questionamentos por parte do público e de colegas quanto à veracidade do que foi noticiado, permitem com que os jornalistas não precisem despender muito tempo na verificação das informações obtidas e possam cumprir com suas deadlines (WOLF, 2003).

Nesse sentido, as fontes oficiais, de um modo geral, são dotadas de poder político e/ou econômico e ocupam posições de expertise e/ou de autoridade formal, e, por isso, são consideradas mais confiáveis, além de permitirem uma produção de 
notícias mais fácil e célere, já que costumam fornecer as informações mais ou menos nos moldes exigidos pela produção redacional. Assim, o uso de fontes oficiais acaba por tornar-se automático, parte da rotina de produção de notícias e homogeneizante das mesmas (BATALHA, 2010; JASPER, 2016; WOLF, 2003).

Nessa discussão sobre as fontes, ao menos quatro aspectos devem ser sublinhados para nossa análise. Primeiro, as fontes não se limitam a indivíduos, mas incluem o próprio meio jornalístico, ou seja, o consumo pelos jornalistas do que outras empresas de mídia produzem nacionalmente e internacionalmente. Esse é mais um fator que contribui para a tendência à homogeneização das notícias e das práticas de produção informacional (WOLF, 2003).

Segundo, a escolha das fontes é uma das causas do enviesamento das informações noticiadas. As fontes oficiais, por quem são e as posições que ocupam, tendem a reproduzir e reafirmar estereótipos e concepções socialmente aceitas e compartilhadas. Decorre disso que a grande mídia tende também, na forma com que seleciona eventos, temas e fontes, a mimetizar as hierarquias e estereótipos presentes na sociedade, apresentando-os de forma naturalizada (WOLF, 2003).

No campo da política, de forma mais específica, a mídia hegemônica tende a agir de modo a reafirmar o status quo ao estabelecer as fronteiras do que é considerado político e das formas legítimas de se fazer política em relação às instituições, seus atores e dos processos que ocorrem em seu âmbito, excluindo ou minimizando a importância política daquilo que não se encontra nesse espectro.

Sem mecanismos de regulação e responsabilização dos canais de mídia tradicional, portanto, foram e são excluídos sistematicamente discursos, grupos e acontecimentos que não ocupam posições de poder e, junto a isso, os conflitos sociais existentes na realidade concreta, que são irremediavelmente políticos, também são acachapados. Como afirma Biroli (2013, pp.135):

\footnotetext{
A seleção dos temas e atores que fazem parte do noticiário produz, assim, um esvaziamento dos conflitos. Não estou ressaltando o fato de que fiquem de fora análises dos conflitos sociais e políticos, interpretações das conexões entre os conflitos sociais e as posições manifestas no campo da política. Estas estão ausentes em grande medida, sem dúvida. Mas refiro-me aqui aos conflitos sociais e políticos de uma maneira menos elaborada ou, se quisermos, "pré-reflexiva". Estão ausentes os "ruídos" que são parte das relações sociais de poder nas sociedades democráticas, indícios de interesses que não são acomodados facilmente, vestígios dos antagonismos que colocariam em xeque os enquadramentos predominantes na política e no jornalismo.
} 
Desse modo, a grande mídia contribui para que as fronteiras do político e as exclusões e relações de dominação existentes na realidade social permaneçam fora de discussão, sejam naturalizadas, e, assim, cria obstáculos para que transformações nessas relações e estruturas aconteçam.

Terceiro, mesmo quando os movimentos de contestação - e outros grupos que enfrentam diversas opressões e exclusões na realidade concreta - alcançam alguma representação ou espaço na mídia, são, geralmente, carregados de estereótipos negativos. Não só o noticiário, mas o cinema, a publicidade, novelas, e outros tipos de produtos midiáticos, costumam utilizar de estereótipos em suas representações da realidade. É importante destacar, antes de dar seguimento à discussão, que os estereótipos não são exatamente uma visão falsa da realidade, mas sim atalhos cognitivos socialmente construídos, compartilhados e naturalizados, utilizados por todos nós de forma a simplificar e interpretar a realidade (BIROLI, 2011, pp. 75-76).

Mais que organizadores de esquemas interpretativos individuais, os estereótipos atribuem papeis sociais e orientam as formas com que as pessoas se enxergam e como são enxergadas pelos outros. Deste modo, impactam diretamente na configuração de relações de poder e traduzem-se em desigualdades de acesso a condições materiais, a determinados espaços ou posições na sociedade e em diversas formas de opressão (BIROLI, 2011, pp. 78-80).

Utilizando estereótipos em seus enquadramentos noticiosos, os meios de comunicação são capazes de facilitar a recepção e interpretação das notícias por públicos diversos já que, ao ativarem referenciais socialmente compartilhados e internalizados, conseguem com que o público se familiarize e seja capaz de dar sentido ao que está sendo representado ${ }^{4}$ (BIROLI, 2011, pp. 89-92).

Depreende-se disso que a seleção dos acontecimentos relevantes de serem publicados, as fontes escolhidas e o enquadramento no qual a notícia é colocada, apoiam-se em estereótipos dominantes, que, sendo apresentados como dados da realidade e não como questões a serem discutidas, são validados e perpetuados, bem como seus impactos concretos nas vidas das pessoas pertencentes a grupos que carregam estereótipos desvantajosos (BIROLI, 2011, pp. 92-93).

\footnotetext{
${ }^{4}$ Este mecanismo, importante ressaltar, não é análogo à manipulação, já que só funciona porque a construção e a adesão aos estereótipos antecedem sua reprodução nos meios de comunicação (BIROLI, 2011, pp. 89-90).
} 
Ademais, o fato de que seus discursos e sua visão da realidade sejam colocados em um patamar de menor importância em comparação com as fontes oficiais, dificulta, também, que esses grupos tenham a oportunidade de que suas demandas entrem na agenda do público, que é uma das principais ambições que levam grupos ativistas a tentarem chamar a atenção da grande (BIROLI, 2011; MIGUEL, 2002).

Como explicita JASPER (2016, p. 183-184)

\begin{abstract}
Eles (os jornalistas) tentam apresentar matérias capazes de atrair o público, o que com frequência significa o relato de indivíduos, com algum suspense, sobre ações e não sobre a situação do momento, e especialmente formas de ação incomuns e fotogênicas. Apenas alguns protestos são considerados "midiáticos". E somente alguns manifestantes: enquanto as autoridades governamentais têm quase sempre garantido o status de fontes legítimas de notícias a serem entrevistadas, manifestantes raramente desfrutam dessa condição. Eles recebem cobertura mais por suas ações que por suas opiniões, sobretudo quando essas ações ameaçam infringir a lei. Os editores muitas vezes apresentam os protestos como caso de polícia, mostrando os manifestantes como potenciais infratores.
\end{abstract}

Em quarto, e por fim, a escolha das fontes e a seleção dos eventos da realidade concreta merecedores de serem noticiados não devem ser entendidas de forma ingênua. A disputa pelo acesso aos media é nada menos que a disputa pela possibilidade de construir um determinado enquadramento da realidade, de relações que nela se estabelecem e dos atores e atrizes que nela existem. É, portanto, uma disputa de poder (WOLF, 2003; CASTELLS, 2013).

Assim, parece interessante que os movimentos sociais busquem a criação de seus próprios meios de produção informacional, não só porque a capacidade de produzir visões de mundo aceitas significa poder nas sociedades contemporâneas, mas para que façam com que o público conheça sua versão dos fatos, sua interpretação de si mesmos. Para muitos, as possibilidades de concretizar essa ambição estaria na internet, e é sobre isso que trataremos no próximo capítulo (BATALHA, 2010; JASPER, 2016; CASTELLS, 2013; PEREIRA, 2011). 


\section{CAPÍTULO 2 - INTERNET E TRANSFORMAÇÕES SOCIAIS}

Recentemente observamos o nascimento e as ações de movimentos importantes não somente pelas transformações que conquistaram em seus respectivos países de origem, mas também por sua extensão e pelo intenso uso de novas tecnologias de comunicação e informação (TICs). O movimento Zapatista, no México, considerado o inaugurador do ciberativismo, a chamada Batalha de Seattle, que teve como resultado a criação do Indymedia (Centro de Mídia Independente), as mobilizações que aconteceram na Tunísia e na Islândia e que foram seguidas pela Primavera Árabe, pelos Indignados da Espanha, pelo Occupy Wall Street e, no Brasil, pelas Jornadas de Junho de 2013, são exemplos desses movimentos, que ganharam a atenção da mídia internacional e dos estudiosos de ativismo político (ALCÂNTARA, 2015; CASTELLS, 2013).

Várias foram as pesquisas que, a partir da observação dos exemplos empíricos citados, procuraram compreender o papel das novas tecnologias de informação e comunicação no ativismo contemporâneo. Essas pesquisas, geralmente, partem do entendimento de que os movimentos de contestação, a partir da segunda metade do século XX, abandonariam a luta de classes como orientadora de sua ação conflituosa e passariam a atuar no território das identidades de indivíduos e grupos e das disputas simbólicas (MACHADO, 2007; ALCÂNTARA, 2015; ABERS E BÜLOW, 2011).

Isso porque, com o declínio do socialismo real e a vitória do capitalismo, observaríamos a consolidação das democracias liberais que, supostamente, legitimariam a existência de grupos ativistas. Dessa forma, os embates não seriam mais empreendidos em oposição ao Estado, mas com vistas ao aprofundamento democrático e, por vezes, em negociação com o próprio Estado (MACHADO, 2007; ALCÂNTARA, 2015; ABERS E BÜLOW, 2011).

Outra nota característica desses movimentos seria a organização em rede, de forma a garantir descentralização e horizontalização internas, e o uso das novas tecnologias de informação, principalmente da internet, com vistas a alcançar esses objetivos. O termo rede transmite as ideias de articulação, de conexão, de comunicação, e é sobre essas ideias que o conceito de redes sociais, em suas diversas acepções, estrutura-se (MACHADO, 2007; ALCÂNTARA, 2015; CASTELLS, 2013, 2015). 
Acioli (2007) divide o uso desse conceito em três: um metafórico, um analítico e um tecnológico. No uso tecnológico, afinado aos estudos a que nos referimos, as redes sociais diriam respeito à possibilidade de contato e troca informacional entre grupos ou pessoas de forma mediada pelas novas tecnologias de comunicação e informação.

Haveria, pois, uma congruência entre a organização no formato de redes sociais e a busca por horizontalidade e produção simbólica dos grupos de ativismo político contemporâneos.

Nesse sentido, muitos autores, tendo por base o entendimento de que a internet funcionaria conforme um modelo distribuído de comunicação, interpretaram o advento dessas novas tecnologias, e principalmente da internet, como uma possível via de escape à mídia tradicional, pela qual movimentos em rede impulsionariam mudanças sociais (BATALHA, 2010; CASTELLS 2013; 2015).

Isso porque nesse modelo distribuído de comunicação, supostamente, inexistiriam quaisquer filtros através dos quais as informações passariam no processo de transmissão entre o emissor e o receptor. Assim, as informações estariam livres do processo de seleção e tratamento realizado pelos jornalistas nos media tradicionais (PEREIRA, 2011; BARAN, 1964 apud BATALHA, 2010).

Além disso, as posições de emissor e receptor não seriam fixas: todos os envolvidos no processo comunicacional mediado pela internet poderiam ocupar ambas as posições, caracterizando um verdadeiro processo comunicativo (PEREIRA, 2011; BARAN, 1964 apud BATALHA, 2010).

A mídia tradicional, ao contrário, seria caracterizada pela centralização, ou seja, os receptores nunca ocupariam a posição de emissores e dependeriam da seleção feita exclusivamente pelos jornalistas profissionais para se informar. No máximo, a mídia tradicional adquiriria um formato descentralizado, que pode ser interpretado com um conjunto interligado de diversos processos comunicativos centralizados em uma menor escala (BARAN, 1964 apud BATALHA, 2010).

A imagem a seguir pode ser útil ao entendimento de como se conformariam os modelos de comunicação centralizados, descentralizados e distribuídos. 


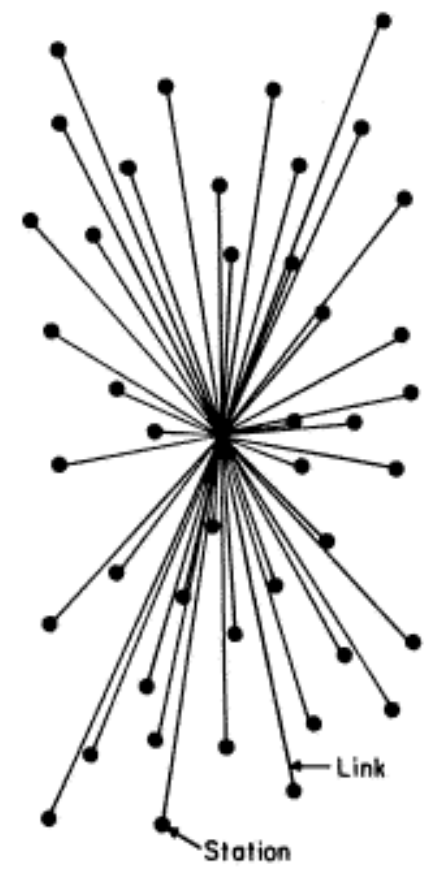

Rede centralizada

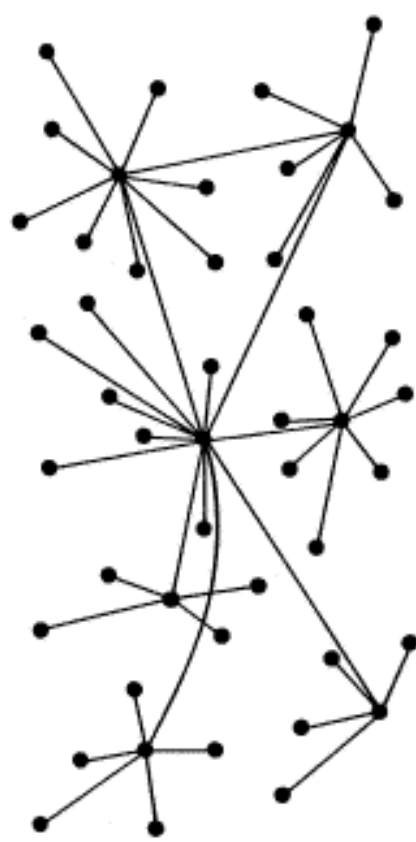

Rede descentralizada

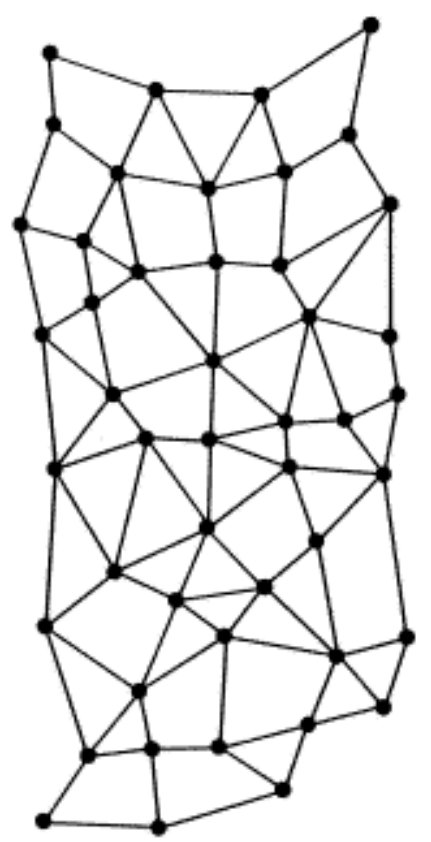

Rede distribuída

Fonte: BARAN, 1964, p. 2 apud BATALHA, 2010, pp. 52

Ademais, as novas tecnologias de informação e comunicação permitiriam a efetivação do modelo de organização em redes sociais, garantindo a descentralização e horizontalização das relações, além da autonomia dos nós conformadores da rede. Desse modo, uma das questões centrais para o modelo distribuído em que essas redes conformam-se está no fato de que "um eventual enfraquecimento ou eliminação de um ponto nodal dessa rede não afeta significativamente a estrutura entre os movimentos que a compõem (JUNIOR E ROCHA, 2013, pp. 210)”. As mídias tradicionais, ao contrário, não permitiriam esse grau de autonomia entre seus nós e, portanto, qualquer alteração em um de seus pontos seria responsável por afetar os demais (BARAN, 1964; BATALHA, 2010).

A partir da internet abrir-se-ia, portanto, a oportunidade de que grupos marginalizados pudessem produzir suas próprias informações e difundi-las de forma rápida, ampla e a baixos custos, alcançando, portanto, espaço no debate público para a discussão do que, em geral, é apresentado como dado natural e imutável da realidade pela mídia empresarial. Ao extremo, a internet, através das redes sociais virtuais, permitiria um tipo de participação e interação que seria, supostamente, equivalente ao modelo de democracia direta (PEREIRA, 2011; MACHADO, 2007; MIGUEL, 2000, pp. 135; BATALHA, 2010). 
Manuel Castells é uma das referências dessa vertente de estudiosos que defendem as potencialidades da internet e das plataformas digitais e, por isso, escolhemos esse autor para orientar as discussões que empreenderemos a seguir.

É preciso ressaltar, de início, que, para compreender o ativismo contemporâneo e os processos de mudanças sociais, Castells parte do entendimento de que vivemos em uma sociedade em rede, que conceitua como

\begin{abstract}
[...] uma estrutura social baseada em redes operadas por tecnologias de comunicação e informação fundamentadas na microeletrônica e em redes digitais de computadores que geram, processam e distribuem informação a partir de conhecimento acumulado nos nós dessas redes. A rede é a estrutura formal (vide Monge e Contractor, 2004). É um sistema de nós interligados. E os nós são, em linguagem formal, os pontos onde a curva se intersecta a si própria (CASTELLS, 2006, pp.20).
\end{abstract}

Ao fazer essa caracterização da sociedade em rede, Castells argumenta que a novidade não está no fato de serem baseadas no conhecimento ou na informação, nem mesmo que tenham as redes como forma de organização social, mas no fato de que a já existente organização em redes teria adquirido uma nova dimensão a partir do surgimento das redes de comunicação digital (CASTELLS, 2006).

Explicando melhor, as redes sociais se refeririam às interações travadas entre os diversos atores presentes na sociedade, à formação de laços pessoais e sentimentais entre as pessoas e, portanto, à própria construção de uma sociedade, que passa, necessariamente, por um processo comunicativo (JASPER, 2016; CASTELLS, 2006). A comunicação digital, para Castells, transformaria a configuração das redes sociais, dando dimensões globais e públicas a redes anteriormente restritas ao âmbito local e/ou privado. Além disso, converteria redes sociais antes verticalizadas nas redes descentralizadas responsáveis por dar as feições da sociedade em rede que conceitua (CASTELLS, 2006, 2013).

Essa nova forma de comunicação, para o autor, possibilitaria a interação entre os componentes de uma mesma rede e entre diferentes redes preservando, ao mesmo tempo, a autonomia de cada um desses componentes. Para Castells, portanto, as plataformas virtuais permitiram uma comunicação essencialmente autônoma, que ele chama de "autocomunicação de massa":

É comunicação de massa porque processa mensagens de muitos para muitos, com o potencial de alcançar uma multiplicidade de receptores e de se conectar a um número infindável de redes que transmitem informações digitalizadas pela vizinhança ou pelo mundo. É autocomunicação porque a produção da mensagem é decidida de modo autônomo pelo remetente, a designação do receptor é autodirecionada e a recuperação de mensagens das redes de comunicação é autosselecionada (CASTELLS, 2013, p. 9-10). 
Seguindo na caracterização desse modelo de sociedade, o autor afirma que também o poder, de forma ampla, passaria a se arranjar em redes (financeiras, políticas, culturais, militares, etc. $)^{5}$. Essas redes seriam diferentes entre si, mas se influenciariam, aliar-se-iam provisoriamente e, todas elas, definiriam ou ambicionariam definir as regras responsáveis por configurar a sociedade (CASTELLS, 2006).

O significado de poder, além disso, não estaria restrito ao monopólio do uso da violência, mas também à hegemonia simbólica. Afinal, Castells entende que a dominação por meio de regras e valores compartilhados diminuiria a resistência dos dominados e, portanto, seria bem mais efetiva do que a baseada somente na coerção física. A disputa entre as diversas redes constituintes da sociedade pela possibilidade de definir regras e valores, nesse sentido, significaria uma disputa por poder (CASTELLS, 2006).

A formação desse poder simbólico aconteceria através de processos comunicativos que têm vez no âmbito público mais amplo, ou seja, aquele que extrapola as interações interpessoais e que depende dos meios de comunicação existentes. Isso posto, mudanças nos padrões de comunicação significariam mudanças na produção da face simbólica do poder e das próprias configurações do poder instituído (CASTELLS, 2006).

O surgimento da internet, nesse sentido, representaria um rearranjo nas relações de poder ao viabilizar a descentralização dos meios comunicacionais, necessários à produção do poder simbólico, antes concentrados nas mãos das elites políticas e econômicas, monopolizadoras da mídia tradicional (CASTELLS, 2006).

Ademais, para Castells, a constituição de um poder produziria, necessariamente, um contrapoder a partir dos ocupantes da posição de dominados. Nesse cenário, o entendimento das redes de contrapoder também teria como requisito a compreensão das formas de comunicação exitentes (CASTELLS, 2006).

Afinal, tendo em mente a centralidade da produção simbólica para a constituição do poder, a existência de um contrapoder implicaria a formulação de um conjunto de significados e interpretações da realidade desafiadores do que está posto como hegemônico. Além disso, a formação de movimentos de resistência pressupõe a

\footnotetext{
${ }^{5}$ Mesmo o Estado deixaria de caracterizar-se como um estado-nação para tornar-se o que Castells (2006) chama de um Estado em rede. Afinal, na sociedade em rede o local/nacional estaria em constante relação com o global/internacional, ou seja, as decisões e ações dos Estados não se limitariam mais às fronteiras nacionais.
} 
existência de um processo comunicativo entre pessoas que compartilham desse conjunto simbólico alternativo, além de determinadas aspirações em relação ao poder instituído (mesmo que seja a destruição completa desse poder) (CASTELLS, 2006).

Partindo do entendimento de Castells, de que esses movimentos "são induzidos por uma profunda desconfiança nas instituições políticas que administram a sociedade" (CASTELLS, 2013, p. 127), faz-se compreensível a afirmação de que muitos grupos ativistas rejeitam os canais de participação política que são disponibilizados pelo Estado (CASTELLS, 2013).

Este distanciamento em relação ao Estado garantiria a permanência de uma nota característica dos movimentos sociais: a autonomia. Esta autonomia "refere-se à capacidade de um ator social tornar-se sujeito ao definir sua ação em torno de projetos elaborados independentemente das instituições da sociedade, segundo seus próprios valores e interesses" (CASTELLS, 2013, p. 135); além da possibilidade de expressar suas ideias, seus valores e seu inconformismo. Ou seja, a formação de um contrapoder exigiria, necessariamente, um processo comunicativo autônomo (CASTELLS, 2006, 2013).

A internet, nesse cenário, seria central, visto que Castells a considera um reduto de segurança, em que o controle dos detentores do poder institucional seria obstacularizado. Seria, assim, um meio de travar um processo comunicativo essencialmente autônomo que, como tal, só é possível de ser realizado fora dos canais midiáticos tradicionais, controlados por empresas privadas e governos estabelecidos (CASTELLS, 2006, 2013).

O autor, pois, assume uma posição em que a internet é, propriamente, um componente essencial da organização social, ou melhor, é mesmo a "espinha dorsal" de um novo modelo organizacional, não se limitando a um papel meramente instrumental. Ela permitiria o nascimento dos movimentos de resistência, sua manutenção, sobrevivência e expansão (além da própria constituição da sociedade em rede) (CASTELLS, 2006, 2013).

Assim, a mudança social aconteceria no desafio às redes de poder dominantes pelas redes desses movimentos, condicionadas pelas redes de comunicação virtuais. Essas, portanto, dariam os contornos dos movimentos contestatórios e, enfim, dos próprios processos de mudanças sociais (CASTELLS, 2006, 2013).

Acreditamos, no entanto, que o autor confere uma importância maior aos impactos das redes virtuais na conformação das sociedades contemporâneas, para a 
prática ativista e, finalmente, para os processos de mudanças sociais do que eles efetivamente representam. Entendemos que, apesar de ter promovido alterações que não podem ser desconsideradas, a internet não faz frente - ao menos ainda não - ao poder da mídia tradicional, concentrada nas mãos das elites econômicas e políticas.

Além disso, os potenciais de horizontalização e descentralização das relações, bem como seu caráter supostamente autônomo, levantam questionamentos que não podem ser ignorados.

Pereira (2011, p. 12), por exemplo, destaca a importância da internet enquanto "instrumento que tem sido utilizado e aprimorado pelos movimentos sociais e que tem promovido mudanças nos repertórios adotados através de novos meios de publicização de informações, novas formas de comunicação e coordenação de mobilizações".

Contudo, esse autor chama a atenção para o fato de que a internet, ainda que ajude significativamente na organização dos movimentos sociais e potencialize seu campo de atuação e seu poder de mobilização, não significou uma ruptura com as outras ferramentas comunicacionais e de articulação existentes. Ela tem sido utilizada de forma combinada com manifestações presenciais, mídia impressa, televisiva e radiofônica, telefone, dentre outras (PEREIRA, 2011).

Mesmo Castells (2013), ao citar em seu livro Redes de Indignação e Esperança os exemplos da Primavera Árabe e das mobilizações no Egito, que encontraram seu ápice nos anos de 2010 e 2011, expõe que uma das formas de repressão vindas do Estado foi o bloqueio de internet, e que "a revolução nunca ficou incomunicável porque suas plataformas de comunicação eram multimodais (CASTELLS, 2013, pp. 44 - 45)". Ou seja, durante os protestos, os movimentos não utilizaram unicamente das plataformas digitais como forma de comunicação e difusão informacional, mas também do rádio, de telefones fixos, faxes, panfletos impressos, entre outras formas de mídias tradicionais.

A repressão por meio do bloqueio da internet enfrentada por esses movimentos também evidencia que o ciberespaço não é exatamente o lugar da liberdade e da segurança para a produção autônoma de redes de resistência, como é afiançado por Castells (2006, 2013). 
O controle sobre as redes virtuais existe ${ }^{6}$. Poucas plataformas são realmente seguras, e o conhecimento de sua existência e funcionamento não é compartilhado entre muitos. Mas, certamente redes virtuais como Facebook, Twitter, YouTube, Gmail, Whatsapp, não estão entre essas plataformas seguras à comunicação autônoma ativista, já que são produto de empresas e facilmente acessíveis para governos. Como ressaltam (JUNIOR E ROCHA, 2013, pp. 208)

Se a Internet foi concebida inicialmente "sem que as grandes corporações percebessem a sua importância" (PRETTO; SILVEIRA, 2008, p. 35), hoje, essa grande rede "já é controlada em vários países, que se utilizam de filtros para censurar, seja usando palavras-chave para bloquear mensagens ou manipulando resultados de buscas, eliminando deles o que é considerado ameaça" (NABUCO, 2012, p. 42). Costa (2013, p. 23) afirma que "temos agora a evidência do monitoramento da telefonia e da Internet", referindo-se às revelações de Edward Snowden, ex-agente da CIA10, a respeito das interceptações de conteúdos de conversas de usuários da Internet, pelo programa de computador PRISM da Agência de Segurança Nacional (NSA) dos Estados Unidos. Atualmente, são os algoritmos criados pelas grandes empresas de software que definem o conteúdo que será exibido na tela do computador. "Antes, ao se seguir alguém no Facebook, tinha-se acesso a tudo o que era postado. Agora, a rede social mostra ou esconde postagens segundo seus próprios critérios" (COSTA, 2013, p. 24).

Também Jasper (2016, pp. 102) ressalta que:

Prosseguem as lutas por essa mídia, não tão descentralizada quanto parece, mas dependente de grandes empresas que podem encerrar serviços e permitir a censura e o monitoramento sub-reptício por parte do governo.

Finalmente, ao falar do Occupy Wall Street, ocorrido em Nova Iorque, no ano de 2011, o próprio Castells exemplifica o argumento que defendemos:

[...] o movimento baseava-se em plataformas comercialmente disponíveis, prontas para serem usadas. Desse modo os militantes se tornaram vulneráveis a intimações para fornecer informações sobre tuítes, para violar a privacidade dos usuários com conseqüências potencialmente graves (CASTELLSls, 2013, pp. 109).

Ao mesmo tempo, o autor admite que a comunicação "livre" no ciberespaço, por si só, não é elemento suficiente para a existência e sobrevivência de movimentos disruptivos. Falando sobre a revolução no Egito, o autor coloca que

O papel das redes sociais off-line preexistentes também foi importante, já que elas facilitaram a disseminação de panfletos nas favelas digitalmente excluídas, assim como as formas tradicionais de reunião social e política nas mesquitas após as orações das sextas-feiras (CASTELLS, 2013, pp.42).

\footnotetext{
6 "Ativistas tentam disseminar suas idéias o mais amplamente possível, mas, na maioria dos casos, quanto maior o veículo, menor o controle que têm sobre a mensagem transmitida. Desde o século XIX, novas tecnologias de comunicação têm ajudado os movimentos sociais - mas também apoiado esforços para monitorá-los e reprimi-los (JASPER, 2016, pp. 101).”
} 
Por conseguinte, as relações pessoais que são travadas cotidianamente por todas as pessoas são indispensáveis para o nascimento, o processo de mobilização, expansão e manutenção de um movimento ativista. Como defende JASPER (2016, pp. 106)

\begin{abstract}
Essa é uma das razões pelas quais grandes protestos podem surgir tão rapidamente: já há uma infraestrutura para ajudar a mobilizar pessoas. Esta consiste não apenas numa lista de telefones ou emails (ou cartões de Natal, para os militantes cristãos), mas também em padrões de confiança, respeito e afeição que envolvem as pessoas num nível emocional. Elas podem alimentar entre si a indignação, o ódio, a compaixão e outros sentimentos que acabarão servindo de apoio ao protesto público.
\end{abstract}

Além disso, é importante considerar que vivemos em uma sociedade com profundas desigualdades sociais e econômicas. Dessa forma, uma parcela significativa da população ainda não possui acesso à internet. No caso brasileiro, de acordo com a Pesquisa Nacional por Amostra de Domicílios (IBGE, 2016), a televisão ainda é o principal media encontrado nas casas brasileiras, alcançando praticamente sua totalidade, e até mesmo o rádio ainda encontra uma maior penetração que a internet.

\begin{tabular}{|c|c|c|}
\hline & $\begin{array}{c}\text { Domicílios em } \\
\text { que existe } \\
\text { utilização da } \\
\text { internet (\%) }\end{array}$ & $\begin{array}{c}\text { Domicílios em } \\
\text { que não existe } \\
\text { a utilização da } \\
\text { internet (\%) }\end{array}$ \\
\hline Norte & 45,1 & 54,9 \\
\hline Nordeste & 44,8 & 55,2 \\
\hline Centro-Oeste & 60,9 & 39,1 \\
\hline Sudeste & 66 & 34 \\
\hline Sul & 61,3 & 38,7 \\
\hline Brasil & 57,8 & 42,2 \\
\hline
\end{tabular}

Fonte: IBGE, Diretoria de Pesquisas, Coordenação de Trabalho e Rendimento, Pesquisa Nacional por Amostra de Domicílios 2016.

De acordo com essa pesquisa, o uso da internet estava em pouco mais de metade dos domicílios brasileiros, encontrando variações significativas entre áreas urbanas e rurais $(63,9 \%$ dos domicílios na área urbana para $21,2 \%$ dos na área rural) (IBGE, 2016, pp. 40). Quando analisado o uso da internet por pessoas, ainda, o acesso à internet cresceria conforme aumentassem os patamares de renda e escolaridade (IBGE, 2016, pp. 49, 52). 
Essa foi uma das questões, inclusive, citadas por Castells ao perceber a importância do uso multimodal dos media e dos encontros e redes pessoais. Castells compreende que existe uma grande parcela de pessoas excluídas do acesso ao que chama de sociedade em rede, mas afirma que, mesmo não tendo acesso a ela, "toda a humanidade é afetada por sua lógica" (CASTELLS, 2006, pp. 18). Mas, se é justamente a possibilidade de democratização do processo comunicativo e de um tipo de revolução no acesso aos media que a internet representaria, o fato de que tamanha exclusão exista parece agir justamente na direção contrária a esse argumento.

Mesmo partindo do pressuposto de que estejamos em uma sociedade em rede e de que as redes de poder existentes influenciem a vida de todos, a exclusão da maioria da população dessa conformação significaria acrescentar mais uma exclusão oas dominados. As possibilidades de mudanças sociais vindas dos excluídos seria, ainda, uma problemática.

Outra questão a ser destacada é a importância das demonstrações e da ocupação do espaço público. Mesmo que, por vezes, pareça limitar a função da ocupação urbana, de encontros e outras formas de ativismo que têm vez na realidade concreta à construção de espaços de comunicação autônoma, Castells reconhece a necessidade de que essas ações existam.

\footnotetext{
Uma vez que o espaço público institucional - o espaço constitucionalmente designado para a deliberação - está ocupado pelos interesses das elites dominantes e suas redes, os movimentos sociais precisam abrir um novo espaço público que não se limite à internet, mas se torne visível nos lugares da vida social. É por isso que ocupam o espaço urbano e os prédios simbólicos (CASTELLS, 2013, pp. 12).
}

Há que se pensar, ainda, que o que impulsiona o ativismo e a mobilização das organizações da sociedade civil em prol de uma causa tem lugar no espaço offline, ou seja, as demandas e conflitos surgem, na maior parte das vezes, no mundo real e não no virtual. Assim, exceto no caso de movimentos hackers, o foco de movimentos disruptivos está em resolver problemas e enfrentar conflitos que estão para além da internet (PEREIRA, 2011).

Por fim, a capacidade de produzir informações capazes de alcançar um número de pessoas que ultrapasse um círculo bastante restrito de conhecidos, mesmo nas mídias virtuais, ainda é restrita aos que possuem reconhecimento público, como as celebridades, ou a mídia hegemônica (LIMA, 2010; MIGUEL, 2000). Como afirma Biroli (2013, pp. 129): 
[...] o jornalismo online pode ser entendido como um elo a mais na alimentação de informações entre jornalistas, e entre jornalistas e assessorias de imprensa, aqui discutida. As manifestações dissonantes, na internet, tendem a não atingir o mesmo status que os blogs e twitters de jornalistas e políticos já posicionados.

Dessa feita, os discursos divergentes (contrapoder) ainda não conseguem competir com o poder de agendamento monopolizado pela mídia hegemônica, para a qual a internet representou mais um meio de difusão de suas interpretações da realidade (poder). Importante ressaltar que o processo excludente de produção de notícias utilizado pelos jornalistas na mídia empresarial continua a ser aplicado na internet, ou seja, são basicamente as mesmas notícias veiculadas por seus canais tradicionais (BIROLI, 2013; LIMA, 2010).

Assim, ainda que a internet não possa ser ignorada e tenha um impacto inegável na dinâmica das sociedades contemporâneas, ela não representou deslocamentos tão profundos como defendidos por Castells. E, ainda que representasse, o poder da mídia hegemônica ainda existiria e teríamos, como agora, que lidar com a necessidade de uma democratização do acesso e da posse dos media tradicionais (MIGUEL, 2000). 


\section{CAPÍtULO 3 - A ENGAJAMUNDO E O USO DA INTERNET PARA O ATIVISMO}

É certo que a internet tem impactos nas sociedades contemporâneas e para as ações de movimentos disruptivos que não podem ser ignorados. O que não está claro, ainda, é a extensão desses impactos e se são abertas novas rotas para que transformações sociais aconteçam.

No intento de discutir sobre as possibilidades e limites que a internet representa para processos de transformações sociais empreendidas através do ativismo, utilizaremos do exemplo da Organização Não-Governamental (ONG) Engajamundo.

Conforme está posto em seu site oficial e as falas dos entrevistados, a Engajamundo teve início em 2012, quando alguns alunos do curso de relações internacionais da Pontifícia Universidade Católica de São Paulo (PUC-SP) fizeram um comitê para ir à Conferência das Nações Unidas para o Desenvolvimento Sustentável, a RIO+20. Segundo relataram membros fundadores, ao perceberem que a juventude brasileira não estava bem articulada para representar o país e discutir as diferentes demandas apresentadas na Conferência, decidiram criar a ONG. Seu objetivo primordial, portanto, seria o de capacitar a juventude brasileira de forma que conseguissem efetivamente participar e apresentar as demandas do país em reuniões e Conferências internacionais.

A participação na ONG é restrita a pessoas que encontram-se dentro da faixa etária que a ONU define como "jovens", ou seja, a organização é composta exclusivamente por pessoas entre 15 e 29 anos. Este é o único critério elencado pela Engajamundo para a entrada de novos membros, bastando aos interessados enviar um pedido online ou entrar em contato com algum integrante.

Internamente, a organização divide-se em grupos de trabalho baseados em cinco temáticas orientadoras de suas discussões e de sua atuação ativista, são elas: gênero, biodiversidade, cidades, clima e desenvolvimento sustentável. Cada integrante escolhe em qual temática e grupo de trabalho deseja atuar e cada grupo de trabalho conta com um ou dois coordenadores.

Além disso, existiriam os núcleos locais, voltados à discussão e participação ativa em questões locais das cidades e regiões onde existem grupos de integrantes da 
Engajamundo. As ações locais iriam desde flashmobs $^{7}$ e participações em protestos à intervenções artísticas nos espaços físicos das cidades.

De acordo as informações conseguidas em sua página oficial, as ações da ONG, atualmente, são realizadas a partir de quatro eixos distintos: a formação dos jovens membros por grupos de estudo online de acordo com as temáticas dos grupos de trabalho e direcionados aos debates empreendidos (principalmente pela ONU) em eventos internacionais; eventos e oficinas presenciais relacionados às temáticas dos grupos de trabalho; participação dos jovens delegados em conferências e negociações internacionais.

A escolha pela realização das discussões em redes virtuais teria como objetivo permitir a participação conjunta de todos os membros espalhados pelo país nas atividades mais cotidianas da Engajamundo. Essas redes permitiriam que desde os horários das reuniões à escolha de delegados para participação nas conferências fossem escolhidas por todos os membros. Além da participação nas reuniões de discussão e estudo realizadas com vistas à formação objetivada pela ONG.

A manutenção financeira da organização é feita por doações realizadas em plataformas online, ou seja, formalmente, não há a opção de entregar contribuições a membros específicos ou em um contato pessoal. Os membros, por sua vez, participam da ONG voluntariamente, não recebem qualquer tipo de remuneração por sua atuação.

Vale ressaltar, enfim, que a estrutura da Engajamundo é composta por um Comitê Facilitador, sediado em São Paulo, que cuida das atividades administrativas da ONG, como, por exemplo, questões de comunicação, arrecadação de fundos, prestação de contas financeiras, coordenação de redes virtuais e divulgação de enquetes para escolha de delegados com vistas à participação em fóruns internacionais.

Como dito anteriormente, o exemplo da Engajamundo nos fornece a oportunidade de observar empiricamente as discussões travadas sobre as possibilidades

\footnotetext{
${ }^{7}$ Para Albacan (2014, pp. 13-14) "flashmobs são atos performativos que reconectam indivíduos com seus ambientes de modo coletivo, criativo e lúdico, desafiam a rotina do dia-a-dia e o modo dominante e passivo de pensar e se relacionar com o seu entorno, e, sobretudo, acontecem dentro de um intervalo de tempo breve e definido - sendo a brevidade essencial para o impacto - enquanto instigam os espectadores (passantes ou públicos dos meios digitais) a engajarem-se ativamente no ato da performance com seu self coletivo momentâneo, tanto por meio de envolvimento corporal como pela disseminação do conteúdo visual gravado [...] Além disso, gostaria de sugerir que, por causa da própria ocorrência na esfera pública e da dramaturgia particular que propõe, a qual procura, abertamente, interromper o fluxo da vida cotidiana e desafiar o discurso social hegemônico, os flashmobs são implicitamente políticos, pois tendem a colocar em questão valores e tópicos atuais."
} 
e os limites que se abrem com o surgimento das novas tecnologias de informação e comunicação.

De partida, é evidente que a capacidade de fazer discussões regulares com a participação de membros residentes em diferentes regiões do país, ou, por exemplo, de montar uma enquete para votação entre os membros da ONG com vistas a escolher delegações para participação em Conferências internacionais, existe de forma interativa e rápida graças às plataformas digitais.

No entanto, há que se atentar para o fato de que as discussões regulares feitas entre os membros da Engajamundo só são possíveis virtualmente por contarem com um número limitado de participantes. Em um cenário no qual grupos muito maiores tentassem reproduzir a mesma atividade, possivelmente "o debate envolveria tantos participantes que seria impossível acompanhá-lo. Todos poderiam falar, mas ninguém teria interlocutores (MIGUEL, 2000, pp. 137).”

Além disso, os entrevistados ressaltam a importância dos encontros nacionais e regionais e dos núcleos locais na construção de laços pessoais entre os integrantes da $\mathrm{ONG}$, de modo a caracterizar uma rede incentivadora da participação ativa e da permanência dos membros na organização. Conforme, afirma a coordenadora de redes:

\begin{abstract}
As redes virtuais facilitaram muito a comunicação, só que o engajamento das pessoas ele é muito relativo. A gente tem histórico de voluntários que se engajaram muito só conhecendo tudo online. Porém, quando a gente fala de quantidade, é quando as pessoas já conheceram outras pessoas do "Engaja", então, por isso, o boca a boca é muito importante. Só quando rolou um contato pessoal, é que a pessoa se engajou mais, se mobilizou etc. Por isso, a gente identificou que era bem importante fazer essas reuniões nas cidades, com a abertura dos núcleos locais. A internet dá conta da mobilização, mas para passar para outro nível, é necessário o contato pessoal.
\end{abstract}

Há ainda a questão das possibilidades de acesso às novas tecnologias de comunicação e informação. Como ressaltado anteriormente, ainda existe uma desigualdade no acesso à internet, conforma a renda, a escolaridade e residir na região urbana ou rural. Nesse sentido, o coordenador do GT de gênero salienta que:

O que é o desafio hoje é atingir uma pessoa que mora mais afastada da zona urbana e não tem acesso à internet. Aí que chega a barreira da nossa mobilização. Tem essa barreira do acesso. Agora estamos procurando encontrar essas pessoas mais afastadas, para empoderá-las e fazer o trabalho nas regiões delas. Por exemplo, uma menina do Acre, ela vai até Manaus para se encontrar com o pessoal do Engajamundo e voltar para o Acre e realizar os projetos que ela achar necessário e mobilizar mais gente perto dela. 
Por fim, foi uma constante que os entrevistados ressaltassem as ações ativistas que têm vez fora do virtual, sendo praticadas a nível do que denominam como "núcleos locais" e na participação das conferências internacionais. Na concepção deles essas ações são muito importantes para mobilização, para que os membros permaneçam na organização e é através delas que as vitórias políticas da Engajamundo são conquistadas. Dessa feita, a internet é uma ferramenta de comunicação e produção informacional até certo ponto muito importante, mas a ação ativista empreendida na realidade concreta é indispensável.

Vê-se, portanto, que mesmo uma organização com as características da Engajamundo, composta predominantemente por jovens, escolarizados, residentes do meio urbano, encontra diversos limites no uso da internet. 


\section{CONCLUSÃO}

Neste trabalho, portanto, partimos do entendimento de que a mídia pode agir de modo a impulsionar ou criar empecilhos para que mudanças sociais empreendidas por aqueles que são sistematicamente excluídos ou oprimidos aconteçam. Considerando que o acesso aos media é questão importante para o ativismo contemporâneo, tanto pela necessidade de comunicar-se quanto pela capacidade de difundir determinadas interpretações acerca da realidade, discutimos as oportunidades apresentadas pelos meios de comunicação tradicionais e, de outro lado, pela internet (BATALHA, 2010; PEREIRA, 2011).

A mídia tradicional, monopolizada por oligopólios poderosos, apresentaria diversos entraves ao acesso de grupos ativistas, relacionados a um processo de seleção de notícias marcado pela exclusão de grupos que passam por opressões e exclusões na realidade concreta. Além disso, a produção informacional da forma que é feita pelos jornalistas profissionais, quando não exclui sistematicamente determinados grupos e discursos, baseia os enquadramentos das notícias que produzem em estereótipos dominantes que, ao serem reproduzidos na mídia, reforçam as relações de dominação e posições desvantajosas dos grupos que os carregam (BATALHA, 2010; BIROLI, 2011; PEREIRA, 2011).

Tendo isso em vista, para muitos, as novas tecnologias de comunicação e informação, principalmente a internet, representariam a possibilidade de que grupos ativistas pudessem estabelecer um processo comunicativo autônomo, seguro e de forma descentralizada, horizontal e, a partir disso, que se abririam novas oportunidades para que mudanças sociais fossem realizadas (ALCÂNTARA, 2015).

Neste estudo, entretanto, escolhemos um autor de referência no assunto para basear as discussões empreeendidas: Manuel Castells. Esse autor constrói sua teoria sobre uma nova sociedade, a sociedade em rede, baseada no surgimento e no uso das novas tecnologias de comunicação e informação. Para ele, esses novos meios de comunicação permitiriam um processo comunicativo no qual todos poderiam ocupar as posições de emissores e receptores, produzir informações e difundi-las de forma ampla, rápida e a baixos custos (CASTELLS, 2006; CASTELLS, 2013).

Tendo em vista o caráter supostamente descentralizado, seguro, autônomo e horizontal da comunicação através de plataformas digitais, a internet, para o autor, seria componente essencial para o ativismo contemporâneo. As mudanças sociais, nesse 
sentido, seriam necessariamente inseparáveis da internet (CASTELLS, 2006; CASTELLS, 2013).

A partir disso, procuramos discutir de forma crítica as reais potencialidades da internet para o ativismo e para os processos de transformações sociais. Como vimos, a segurança do ciberespaço pode ser contestada pela já conhecida capacidade de governos e empresas de controlar, monitorar e reprimir movimentos disruptivos através de informações advindas das plataformas digitais (JASPER, 2016; JUNIOR E ROCHA, 2013).

Ademais, o contato pessoal e a formação de laços afetivos e de solidariedade, ou seja, a formação das tradicionais redes sociais fora do meio virtual é essencial para o nascimento, crescimento, coesão e sobrevivência dos movimentos. Somado a isso, o acesso às novas tecnologias de comunicação e informação ainda não é tão fácil quanto, talvez, se possa pensar. Desigualdades socioeconômicas impactam diretamente nesse acesso, traduzindo-se em um cenário de exclusão que afeta principalmente grupos já excluídos dos meios de comunicação tradicionais (JASPER, 2016; IBGE, 2016).

Destacamos também que as ações ativistas empreendidas por grupos que sofrem com as relações de dominação existentes voltam-se, geralmente, contra práticas, acontecimentos ou estruturas existentes na realidade concreta, e, também, necessitam empreender demonstrações disruptivas fora da internet. Ou seja, a ocupação, o protesto, as assembléias permanecem essenciais ao ativismo contemporâneo (PEREIRA, 2011).

Por fim, utilizando do exemplo da ONG Engajamundo, atestamos empiricamente que, mesmo para uma organização que não se enquadra nos moldes dos movimentos sociais populares tradicionais, o uso da internet não representa uma panacéia.

Com isso não pretendemos alegar a inutilidade da internet em função do ativismo e das transformações sociais. A internet representa uma nova ferramenta que provou ter impacto no ativismo contemporâneo, mas não significou a resolução dos problemas que enfrentamos atualmente com a concentração da posse dos meios de comunicação e a falta de regulação da grande mídia. Não significou a oportunidade essencial para que movimentos de contestação tenham êxito em empreender transformações sociais, nem mesmo em um nível simbólico.

Ademais, a mídia empresarial estendeu sua influência também às plataformas digitais, isto é, encontrou mais uma forma de ampliar seu poder de 
agendamento. Permanece, portanto, a problemática da dificuldade de acesso de grupos excluídos social, política ou economicamente aos meios de comunicação e, portanto, da necessidade de democratização da mídia. 


\section{REFERÊNCIAS BIBLIOGRÁFICAS}

ABERS, Rebecca; BÜLOW, Marisa von. Movimentos sociais na teoria e na prática: como estudar o ativismo através da fronteira entre Estado e sociedade. Sociologias. Porto Alegre, ano 13, n. 28, set./dez., 2011, pp. 52-84.

ACIOLI, Sonia. Redes sociais e teoria social: revendo os fundamentos do conceito. Inf. Inf., Londrina, v. 12, 2007.

ALBACAN, Aristita Ioana. O Flashmob como Performance e o Ressurgimento das Comunidades Criativas. Rev. Bras. Estud. Presença, Porto Alegre, v. 4, n. 1, p. 8-27, jan./abr., 2014.

ALCÂNTARA, Lívia Moreira de. Ciberativismo e movimentos sociais: mapeando discussões. Aurora: revista de arte, mídia e política, São Paulo, v.8, n.23, p. 73-97, jun.set., 2015.

AZEVEDO, Fernando Antônio. Agendamento da política. In: RUBIM, Antônio Albino Canelas (org.). Comunicação e política: conceitos e abordagens. Editora Unesp, 2004.

BARAN, Paul. On distributed communication: introduction to distributed communication networks. RAND Memorandun, RM-3420-PR, August, 1964.

BATALHA, Marcelo da Luz. Novas fronteiras para a comunicação ativista em rede: um olhar sobre o centro de mídia independente. 2010. 160 fl. Dissertação (Mestrado em Ciência Política). Universidade Estadual de Campinas. Campinas: 2010.

BIROLI, Flávia. Mídia, tipificação e exercícios de poder: a reprodução dos estereótipos no discurso jornalístico. Revista Brasileira de Ciência Política, n. 6, 2011, pp. 71-98.

Limites da Política e Esvaziamento dos Conflitos: o Jornalismo como Gestor de Consensos. Revista Estudos Políticos, n. 6, 2013, pp. 126-143.

BIROLI, Flávia; MIGUEL, Luis Felipe. A produção da imparcialidade: a construção do discurso universal a partir da perspectiva jornalística. Rev. bras. Ci. Soc., São Paulo, v. 25, n. 73, p. 59-76, jun., 2010a.

Visibilidade na mídia e campo político no

Brasil. DADOS - Revista de Ciências Sociais, Rio de Janeiro, vol. 53, n. 3, 2010b, pp. 695 a 735.

CASTELLS, Manuel. Redes de Indignação e Esperança: Movimentos Sociais na era da internet. Rio de Janeiro: Editora Zahar, 2013.

A Sociedade em Rede: do Conhecimento à Política. In: CASTELlS, Manuel; CARDOSO, Gustavo (orgs.). A sociedade em rede: do conhecimento à ação política. Imprensa Nacional - Casa da Moeda, 2006. 
DUARTE, Rosália. Entrevistas em pesquisas qualitativas. Editora UFPR. Revista Educar, Curitiba, n. 24, 2004, pp. 213-225.

ENGAJAMUNDO. Disponível em: www.engajamundo.org. Acesso: 15/11/2017.

ENTMAN, Robert M.. Framing: toward clarification of a fractured paradigm. Journal of Communication, n. 43, Autumn, 1993.

FLYVBJERG, Bent. Case study. In: The Sage Handbook of Qualitative Research. Thousand Oaks, CA: Sage, 2011, chapter 17, pp. 301-316.

IBGE - Instituto Brasileiro de Geografia e Estatística. Pesquisa Nacional por Amostra de Domicílios: Acesso à Internet e à Televisão e Posse de Telefone Móvel Celular para Uso Pessoal. Rio de Janeiro: IBGE, 2016.

JASPER, James M.. Protesto: uma introdução aos movimentos sociais. Rio de Janeiro: Editora Zahar, 2016.

JUNIOR, Gentil Cutrim Serra; ROCHA, Lourdes de Maria Leitão Nunes. A internet e os novos processos de articulação dos movimentos sociais. R. Katál., Florianópolis, v. 16, n. 2, p. 205-213, jul./dez., 2013.

LIMA, Venício A. de. Liberdade de expressão x liberdade de imprensa: direito à comunicação e democracia. São Paulo: Publisher Brasil, 2010.

MACHADO, Jorge Alberto S. Ativismo em rede e conexões identitárias: novas perspectivas para os movimentos sociais. Sociologias. Porto Alegre, Ano 9, n. 18, jul./dez., 2007, pp. 248-285.

McCOMBS, Maxwell E.; SHAW, Donald L.. The Agenda-Setting Function of Mass Media. The Public Opinion Quartely, vol. 36, n. 2, 1972, pp. 176-187.

MIGUEL, Luis Felipe. Os meios de comunicação e a prática política. Lua Nova, n. 55-56, 2002, pp. 155-184.

As novas tecnologias e a democratização da informação.

Lugar Comum, n. 9-10, 2000, pp. 133-145.

PEREIRA, Marcus Abilio. Internet e mobilização política: os movimentos sociais na era digital. Compolítica (paper). 13 a 15 de abril de 2011.

PORTO, Mauro P.. Enquadramento da mídia e política. In: RUBIM, Antônio Albino Canelas (org.). Comunicação e política: conceitos e abordagens. Editora Unesp, 2004.

SZTOMPKA, Piotr. Sociología del Cambio Social. Madrid: Alianza Editorial, 1995.

THOMPSON, John B. Ideologia e Cultura Moderna, teoria social crítica na era dos meios de comunicação de massa. Petrópolis: Editora Vozes, 1995, capítulo 4. 
WOLF, Mauro. Teorias das comunicações de massa. São Paulo: Martins Fontes, 2003.

YIN, Robert K. Estudo de Caso: Planejamento e Métodos. Porto Alegre: Bookman, 2005. 